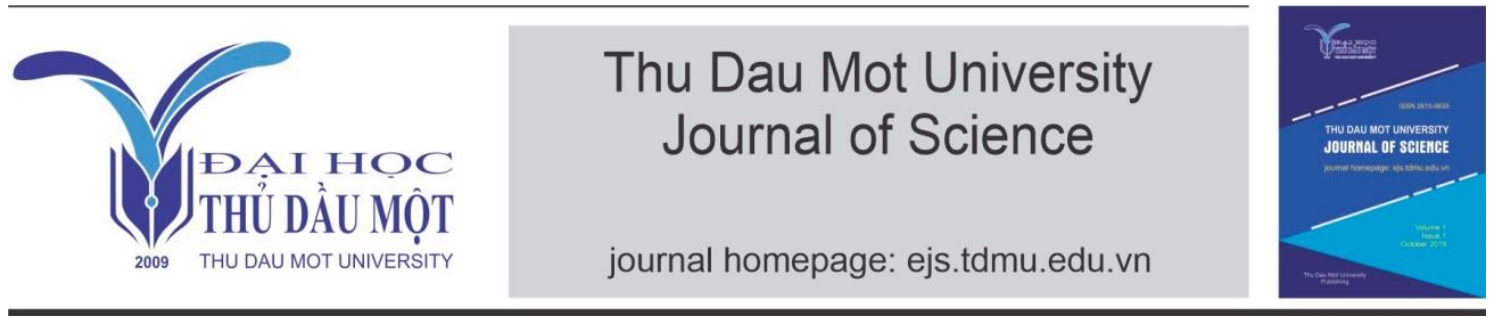

\title{
Leveraging the Youth to A Sustainable Development: A Case Study on A2i Innovation Lab
}

by Tasnia Mahin Rafa, Dola kar (Bangladesh University of Professionals Dhaka); Nargis Islam (ARB Global Research Dhaka - Bangladesh)

Mohammad Osman Gani (Bangladesh University of Professionals Dhaka)

Article Info: Received 1 Nov 2020, Accepted 5 Dec 2020, Available online 15 Dec, 2020

Corresponding author: osman@bup.edu.bd

https://doi.org/10.37550/tdmu.EJS/2020.04.082

\begin{abstract}
Youth in a nation is the most viable and potential human resource in both demographic and social structure. Without the youth's adequate and integrated bio-social development a nation cannot attain its anticipated human goals. Based on government initiative a2 $i$, the empowerment of youth towards sustainable development in Bangladesh is described in this paper. Although the Bangladesh Government has formulated and implemented policies, plans and programs for youth welfare are still through GOs and NGOs. Related literature indicates that, regardless of all age and regions, young people in this country face several sociocultural problems where they cannot grow and empower themselves adequately. As a result, they cannot play their important roles in sustainable development and changes within the country. To resolve the problems of the youth in relation to their development and empowerment, the Government of Bangladesh is developing and implementing some solutions. The case study focuses on the role of a2i for development of youth in the successful design of public development and sustainable development programs.
\end{abstract}

Keywords: Sustainable development Goals, Youth, Innovation, Youth development, Innovation, Empowerment 
Tasnia Mahin Rafa, Dola kar ,...-Volume 2 - Issue 4-2020, p.373-388.

\section{Background}

Youth employment and economic potential are essential components of every society's strong base. It is important for young people and their future to have decent work but it also has a domino impact on economic and sustainable development, communities and the world as a whole. The current challenge is to simultaneously create employment for the bulging youth population and address related issues such as skills gap, working poverty, and the sub optimal transitional school-to - work situation, especially in the developing world. Disadvantaged youth are often more beneficial for developing new opportunities, skills training, providing microcredit, promoting SMEs and investing in education to have the expertise and resources required to compete in the international labor market.

Poverty, literacy rate, unemployment are some major problems in Bangladesh. Unemployment is linked to economic uncertainty in a constructive way. Increased unemployment leads the nation to suffer increased economic vulnerability. Of the total population of Bangladesh, about 50 percent are young people. Yet young people do not find adequate ways to get involved in the economy. The economy cannot move forward without youth. Economic development will never be imagined without the participation of young people. The key issue of youth unemployment is the lack of good governance. Strong governance represents the rule of law. Good governance guarantees the transparency and accountability of a government. Bangladesh needs to establish strong governance in operation. Strong governance curbs corruption. Corruption triggers a rise in the government's operational expenditure. As a result, the budget allowance for public investment is being decreased while the allowance for non-development spending is rising. If the government tries to reduce the youth unemployment rate, it needs to recognize the issues first. Bangladesh aims to reach sustainable development goals (SDGs) within 2030. According SDGs goal 8(5) - 'Promote Sustainable Economic Growth and Employment for All' - a country needs to provide maximum prosperity and decent work for all men and women, including the youths and the people in disadvantaged situations. Therefore, if the government wishes to accomplish SDG-8 within the stipulated time period, it needs to concentrate on growing youth engagement in the economy by providing opportunities for the country's youths.

\section{Introduction}

We know that sustainable development is the concept that society must survive and fulfill its needs, without jeopardizing future generation capacity to meet its own requirements. Sustainable development involves empowering people and communities to cope with the evolving environment, increase social consciousness, increase social engagement and economic participation levels, and explore new insights into ecological 
processes of transition and self-renovation as societies and communities seek to adapt to sustainable patterns in the process of development. To achieve this, we need to strengthen the meaning and reality of the principles of diversity and inclusion, i.e. engaging relevant stakeholders in a process of change; transparency and accountability that gives legitimacy to any process and decisions taken.

Bangladesh has been hailed by the United Nations as well as the international development community as the epitome for socio-economic progress achieved under the Millennium Development Goals (MDGs). The nation has advanced up to lower middle income level, but more importantly, through human development metrics and this achievement came on the back of the nation's stride towards higher per capita income in recent years, riding on steady economic growth. This implies that in achieving the Sustainable Development Goals (SDGs), Bangladesh is well positioned to emerge as a global thought leader.

Many organizations in Bangladesh, take various actions for the good of human communities and their lives for community growth. "a $2 \mathrm{i}$ - innovation for all" is one of them. They strive to unfold the true potential within the government to create extraordinary innovations that can ease and improve the lives of citizens. As the flagship program of the Digital Bangladesh agenda, they believe to inspire developing and developed nations on public service innovation and transformation by sharing their groundbreaking insights supported by examples, lessons, and knowledge. a2i transform the government by their E-governance sector, innovation lab, innovation culture and many other societal work. a2i Innovation Lab brings Bangladeshi youth and entitles them to co-create innovative solutions to development problems. Their main target is to change the social scenario. This is why the lab has split into multiple sectors such as: Innovation fund, Youth Innovation, Skill for employment lab, Agriculture portal, Digital agricultural lab and Disability innovation lab.

\section{Mission, Vision and Objective of a2i Innovation Lab}

Vision: a2i Innovation Lab envisions a lab, where the young innovators dream come true.

Mission: Promoting a hands-on, action-oriented approach to solving society and people's major problems (in areas such as employment, disability rights, and agriculture), laying a strong foundation for some of the best minds to work collaboratively together to generate some of the country's most innovative solutions.

\section{Objective:}

a. To facilitate access to government or private services, facilities and information to the young innovators

b. To create opportunities for women and youth and connecting them to markets and jobs 
Tasnia Mahin Rafa, Dola kar ,...-Volume 2 - Issue 4-2020, p.373-388.

c. To provide market-based solutions to every member of a needy family

d. To solve society's biggest challenges

\section{Youth and Sustainable Development Goal in Bangladesh}

UNDP has been closely engaged with the Planning Commission of Bangladesh to strengthen alignment with the 7th Five Year National Development Plan. 14 goals (82\%) are thematically fully aligned, while three goals (Goal 14, Goal 16 and Goal 17) of the SDGs (18\%) and remaining are partially aligned. (Mukerjee, 2019)

Youth are the backbone of any nation because their proper development relies more on their integrated development. Bangladesh's development also relies on the effective use of its young people since they represent about one-third (15-35 years of age) of the total population (Department of Youth Development, DYD 2009, 30) and 37.7\% of the total civilian work force (Huq 2003, 9). In order to rescue future generation from the catastrophe and to accelerate development process young people must be included in mainstream of development activities. Holding this view, the Government of Bangladesh ( GOB) has implemented youth policy concentrating on youth involvement in all stages of development activities; and the government organizations (GOs) and non-government organizations (NGOs) are conducting variety of activities such as imparting training, offering microcredit, and other support services (monitoring, supervision etc.). Bangladesh is one of the successful countries towards achieving SDGs on action to end poverty, protect the planet and ensure stability and development for all by 2030 . (Mukerjee, 2019) As part of the UN Development system, the United Nations Development Program ( UNDP) has set up four dedicated work streams to assist Bangladesh in its efforts to organize, locate, devise strategies, plans and programs for the sustainable future, access and generate finance, source and analysis data, and accelerate innovation and learning - supporting 17 SDGs. These are crucial building blocks to drive strategies for achieving the SDGs. UNDP is a proud partner with the General Economics Division of the Planning Commission to run the Committee Secretariat to coordinate implementation at policy level, along with tracking and briefing on the status with SDGs. Employment and quality education are the major challenges for Bangladesh in achieving the SDGs. The Department of Youth Development, along with the Ministry of Youth and Sports, has made strenuous efforts to transform the country's youth segment into an organized and productive power. It must be noted that when it comes to tackling youth problems, Bangladesh is facing a paradoxical situation. One third of Bangladesh's total population comprised of young people, so it is highly required to make the youth skilled so that they can contribute to overall national development. With this view, the present government has pursued numerous programs and projects for youth in its overall development strategy. Comprehensive skills development programs for young people 
have been implemented with extensive training in various fields. The government recently implemented some changes in its training process so that time, expense and number of visits to the training program could be reduced.

\section{4. a2i- Innovation Lab to build a skilled youth workforce}

In 2018, Bangladesh's total estimated population was approximately 164.88 million people. (Published by H. Plecher, Apr 22, 2020). In the next ten years, 2 million young people will join the workforce each year with an expected labor force growth rate of 2.2 percent. 0.6 Million of these come from formal education and 1.1 million from government and private organizations. The other forces are graded as NEET (not in Education, Employment and Training). There is therefore a significant difference between the demand for local and international job markets for skilled workers and the availability of educational and training centers. There are several students among them who are university graduates. Such students undertake research projects as part of their regular curriculum, but there is not much effort to turn the few concepts that have emerge into practical solutions. For instance, we see ambitious young entrepreneurs running more than 5,000 Union Information Service Centers in both urban and rural areas, moving beyond their community's call for duty. (Tamesis, 2013) They not only bring government services to the people's doorsteps but also take the lead in addressing social issues like gender equality by providing women with computer literacy training. To capture that very strength, the UN reaffirmed its commitment to the new generation of emerging and present-day world citizens at global level. At the national level, UNDP is exploring innovative ways to integrate youth voices in its numerous initiatives and services, realizing as part of the solution that eradication of poverty can and will not occur without youth.

$\mathrm{a} 2 \mathrm{i}$, as a government innovation partner in collaboration with the UK Cabinet Officebased organization Behavioral Insight Team (BIT), also works for a whole-ofgovernment approach applying behavior change methodologies and the rapid expansion of apprenticeships in Bangladesh to ensure demand-driving skills. a2i plays an important role in the creation of international apprenticeship partnerships. By launching GAN Bangladesh on September 21, 2018, Bangladesh is the 12th country included in the grid as part of the Global Apprenticeship Network (GAN) with a2i. GAN is focused on preparing and improving work-ready opportunities for young people and strengthening skills for business growth. a2i also leads the Alliance for Asia Apprenticeship (AAA) with the Asian countries to share their knowledge, experience and apprenticeship skills. 
Tasnia Mahin Rafa, Dola kar ,...-Volume 2 - Issue 4-2020, p.373-388.

\section{Program under a2i to empower youth}

In recent years, a2i- Innovation Lab started working with the youth. For which they launched new Youth Innovation journey under the a2i Innovation Lab. Their main aim here to make good use of the untapped potential of the students, a2i- Innovation Lab has conceived a multi-pronged strategy to embed the youth's spirit of creativity and engage them in recognizing and solving citizens' problems. Specialists want students to build the youth's energy and creativity to develop innovative solutions to challenges of development through competitions, co-creation and incubation.

In Bangladesh, a2i has formed partnerships with all 137 public and private universities and is slowly engaging the brightest minds of faculty and students in solving the difficult problems facing society today. It is expanding its pool of researchers from industry, who can serve as mentors and innovators. Recently, a2i met experts from nonresident Bangladesh who are serving as mentors for several projects. From an a2iinnovation lab statistics it has been said that about $7160+$ young people are already engaged in innovation and sustainable growth. There are already some 80 youth-led initiatives sponsored for piloting and 137 universities are sensitized to providing hubs for innovation.

\section{a. Skills Development through Industry oriented Apprenticeship Program}

a2i has more than 7000 apprentices from important sectors such as agro-food, mobilizing, tourism \& hospitality, manufacturing, leather \& footwear. This apprenticeship program covers over 250 formal industries. Baking, processing of food, woodworking, polishing lacquer, carpentry, food- and beverage services, cook, housekeeping, plumbing, fitting tiles, manufacturing of clothing, etc. are the most important trade. In addition, the Behavioral Insights Team of the UK Government supports a2i to inspire Bangladeshi companies to follow a learning strategy. a2i also supports training in 1,000 informal jobs in 50 sub-district in rural youth, in cooperation with ILO. a2i promotes education in 50 sub - districts. Similar collaboration with Oxfam Bangladesh has been established to create a 5,500 rural young people apprenticeship program. The Bureau of Manpower, Employment and Training (BMET), will provide participants with certificates of apprenticeship after graduation. a2i is collaborating with the Global Apprenticeship Network (GAN) Switzerland for the establishment of a national training network in Bangladesh. This will allow Bangladesh, along with the rest of the world, to exchange information, experience and innovations. (a2i innovation lab , n.d.)

\section{b. a2i Youth-led Innovation to Development Challenges}

The participation of young people in development programs has very important consequences for their personal growth, their empowerment and their ability to connect 
in their communities with more marginalized people. In order to make good use of the untapped potential of the students, a2i has developed a multi-pronged strategy to inject the spirit of creativity among the youth and engage them in identifying and solving the problems of the people.

a2i undertakes the following programs, as part of this strategy:

Solve-a-Thon: A multi-stage, team-based contest for public and private college students, polytechnic schools, and universities. Design and implementation of the contestant's innovative and implementable approaches to established national problems.

Women's Innovation Camp: A multi-stage, team-based competition for women students to develop and design innovative and implementable approaches to established girls and women affected problems. This camp's two unique features are its distinct emphasis on gender related issues, and girls are expected to be the majority in-squad.

In the case of such competitions, the best project developers earn funding and other forms of support from associated ministries and directorates. In addition, they may apply for a2i's "Service Innovation Fund."

\section{c. Skills Development for Qawmi Madrasha Youths}

In Bangladesh a total of 4 million students across the country studies in 13,902 Qawmi Madrashas. The key drawback of Madrasha education is it only places emphasis on religion education without encouraging other skills that are consistent with today's demand for the modern job market. The government has provided many professional and technical programs and some work opportunities to engage Qawmi Madrasha students with the mainstream. But most students don't have the opportunity to obtain skills to generate income. A2i and the Education board of Qawmi Madrasha "Iqra Bangladesh" jointly collaborated to give Qawmi Madrasha students technical and vocational training in order to turn their lives around through development of skills and job opportunities. Under the skills development program they obtain, along with their traditional curriculum, at least one skill which is very demanded on the local and foreign markets. Currently, up to now more than 25,000 youth obtain education at Qawmi Madrasha in formal and non-formal domains. The program is sponsored by various training providers such as the Department of Social Services, Department of Youth Development (DYD), Bureau of Manpower Employment and Training (BMET), Department of Women Affairs (DWA) and the Bangladesh Road Transport Corporation (BRTC). At present, Qawmi students have acquired a competency in the fields of Electrical House Wiring, Aminship (land survey), Mobile Servicing, Graphic Designing, Tailoring, Block-boutique, Agriculture, Livestock, Horticulture, Driving and Afforestation. This training gives students the opportunity to generate more income and overcome mental and financial limitations, while ultimately benefiting the country in sustainable development. 
Tasnia Mahin Rafa, Dola kar ,...-Volume 2 - Issue 4-2020, p.373-388.

\section{d. Skills development through stipend}

The Access to Knowledge (a2i) Program of Prime Minister's Office in partnership with higher Secondary Stipend Project (HSSP) of the Directorate of Secondary and Higher Education (DSHE) has taken an initiative to incorporate skills development program with the stipend of higher secondary students as the pilot. This initiative's goals are:

- To provide entrepreneurial skills development for the higher secondary students alongside stipend

- To create earning opportunities for higher secondary students alongside their education

- To increase the enrollment of female students in higher secondary education

- To reduce drop out in higher secondary education

The piloting of the program has been completed in 10 Upazillas throughout the country. A total of 200 disadvantaged pro-poor students have gained self-employment and income-generating skills. After completing the training successfully, the students earn money by starting their own business or doing part-time work alongside their education and contributing to their family. Since the pilot program has been a successful one, the government now aims to extend the program to the country's Upazillas.

\section{e. The Green Trishal project}

The Green Trishal initiative has focused particularly on the youth. Through this initiative youth will look after the trees that will definitely lead to the sustainability of the community. This will inspire them to be more accountable, working for the community and country. They will build up their society to be environmentally sustainable and prosperous. The government is building hopes that if only 100,000 trees survive after being given to the students, and if we calculate the cost of each trees as 10 thousand after 10 years the tress prices would be worth 100 core. If each District is motivated by this effort, it will significantly help our country become financially and environmentally more sustainable. This form of initiative will help to bring our country social and sustainable development. Every educational institution has encouraged students and teachers to plant more trees to preserve the environment in order to become a reality.

The theory become reality on 1st October 2016. .During this day thousands of students turned up in Trishal by planting 1, 85,000 trees to create a greener world around them. They each got a health card with trees. In Trishal Upazilla (sub district) 3, 05,000 trees were donated in total. As amazing as it can sound, it took back breaking work to establish strategic plans and execute creative ideas to make this spectacular event successful. Every educational institution gave inspiration to the students and the teachers to plant more trees to protect the environment. Social media has spread the information to everyone about this initiative at a running speed. Upazilla Administration 
planned a distribution strategy while thinking of the benefit of the students: Green Trishal program has been held 1st October 2016 in 12 Union of Trishal. The Upazilla Administration of Trishal considered the benefit of the students and identified three points from which the trees were distributed. The respective authorities were given the list of schools under GP (Gathering Point), SP (Sub Points) and RP (Remote Point). Every school around the gathering point sent out its students to collect trees. The students who cannot collect their trees from the gathering point had SP made for them. Students who lived far away from the gathering point and the sub point gathered their trees from remote points. They also got three types of trees: one fruit tree, one flower tree, and one medicinal tree.

\section{6. a2i's holistic approach}

In context with the situation, the Access to Information (a2i) program proposes four priorities following the strategic framework:

I. Market Analysis, Forecasting and Prioritization: Effective market analysis and forecast can assess the balance in demand, structural non-structural change such as apprenticeship or internship, targeted job assistance, capacity development, incentives, and labor flexibility. Bangladesh has poorly pursued both domestic and foreign markets. Because of inadequate skills and abilities, many employees come from the Middle East and other countries backfires. Training institutions offer many conventional courses and approaches without prior examination of geographical and contextual criteria. The country recently took mega projects such as the Padma Bridge, the metro rail, the elevated express, etc. which would create enormous employment opportunities and would seek skilled workers from home or abroad. Dhaka ranks third in the global outsourcing work but specialized skills development for outsourcing is a crying need to sustain this performance. Thus, market analysis, forecasting the changing environment and prioritizing the skills are suggested as the first strategic priority. a2i and Bangladesh Economic Zones Authority (BEZA) jointly conduct a study on the local market to assess demand and to prioritize the skills development, while the ministry of expatriates and overseas jobs is conducting the study for global markets.

II. Market driven skills development: Every year 400 thousand workers from Bangladesh enter the international job market, all of whom only 25 per cent are trained. With the present capacity of face-to-face training, meeting all the anticipated demand for skills is quite impossible. Therefore, the e/m-learning and blended learning program is very important to address within the capacity building plan. Upto - date market-based and quality learning resources and methodologies need to be 
ensured for on-training and post-training assistance. Training and internship models with a good partnership among both skill providers and industry have a significant impact on job satisfaction and early job placement. a2i has collaborated with various organizations to establish the ties required between the training agencies and the companies in order to pave the way for employees to obtain competitive jobs in different industries. The following are some of the initiatives:

a. Creation of skills in the informal sector in collaboration with ILO through training and employment within 30 Upazillas with 600 informal industries. There are now a total of 1200 rural youth working as apprentices in 35 trades who are on the job.

b. a2i collaborated with the Finance Division's Skills for Employment Investment (SEIP) and BGMEA, to ensure 'equal' facilities for unemployed youth, including the 'plain land ethnic minority groups, to customized skills development facilities and work placement. The two trades - Woven and Knit Machine Service - are currently under surveillance in Sirajganj. The 2-month training program is available to young people aged between 18 and 35 years who want good work in Garment Industry. The participants will earn decent jobs in the garment industry after the successful completion of training.

c. a2 $\mathrm{i}$ is analyzing the nature of the intervention in the Bangladeshi 'Qawmi madrasa framework,' which would potential to revolutionize youth mentality. The present situation is one in which millions of orphans and underprivileged people are subjected to curriculum design that provide little valuable knowledge. a2i strives to inspire thousands and millions of young people to turn their lives around. This intervention would allow them to acquire at least one competence in the local and foreign markets, which is very demanded for sustainable development.

d. Collaboration with the Ministry of Education's Higher Secondary Scholarship Project (HSSP) to combine skill development with scholarship programs. Piloting takes place in 10 upazilas and the self-employment and revenue generating professional workforce of 200 deprived university students.

III. Coordination and standardization: There are 23 ministries, 27 departments, about 7002 institutions for the advancement of public and private skills and several other organizations that are directly involved in skill development. Though all these organizations are working hard but there is still a coordination gap among them tends to cause many overlap of courses, no familiar skill database, and no distinctive or standard certification system and therefore not incorporated properly with labor market. Therefore cooperation between skill providers, firms, industry and standardization of assessment and certification is a prior economic development 
requirement. The National Skills Development Council (NSDC) was formed to coordination and accelerate skills development initiatives, led by the Honorable Prime Minister, to create a connection between various skills development organizations and employment generation. NSDC supports a2i to:

a. Bringing all the players from across the ecosystem together

b. Facilitating the dialogue by discussion of key problems, challenges and opportunities

c. In addition, a2i and NSDC are jointly creating a 'Skills \& Employment' platform to coordinate and monitor all of the country's skill development initiatives.

IV. National Communication and Branding: Through a wide emphasis on TVET, developed countries such as Germany, Switzerland, China and Singapore have dealt with the youth crisis. In Bangladesh, Technical and Vocational Education and Training (TVET) is associated to the perception of students not "making it" in the mainstream education. Improving the image of TVET through appropriate communication and branding is a major national goal. Technology, like social media, is being used to generate an optimistic TVET buzz and to raise awareness about how this can lead to personal prosperity and national sustainable growth.

\section{Strategic Framework of a2i Innovation Lab}

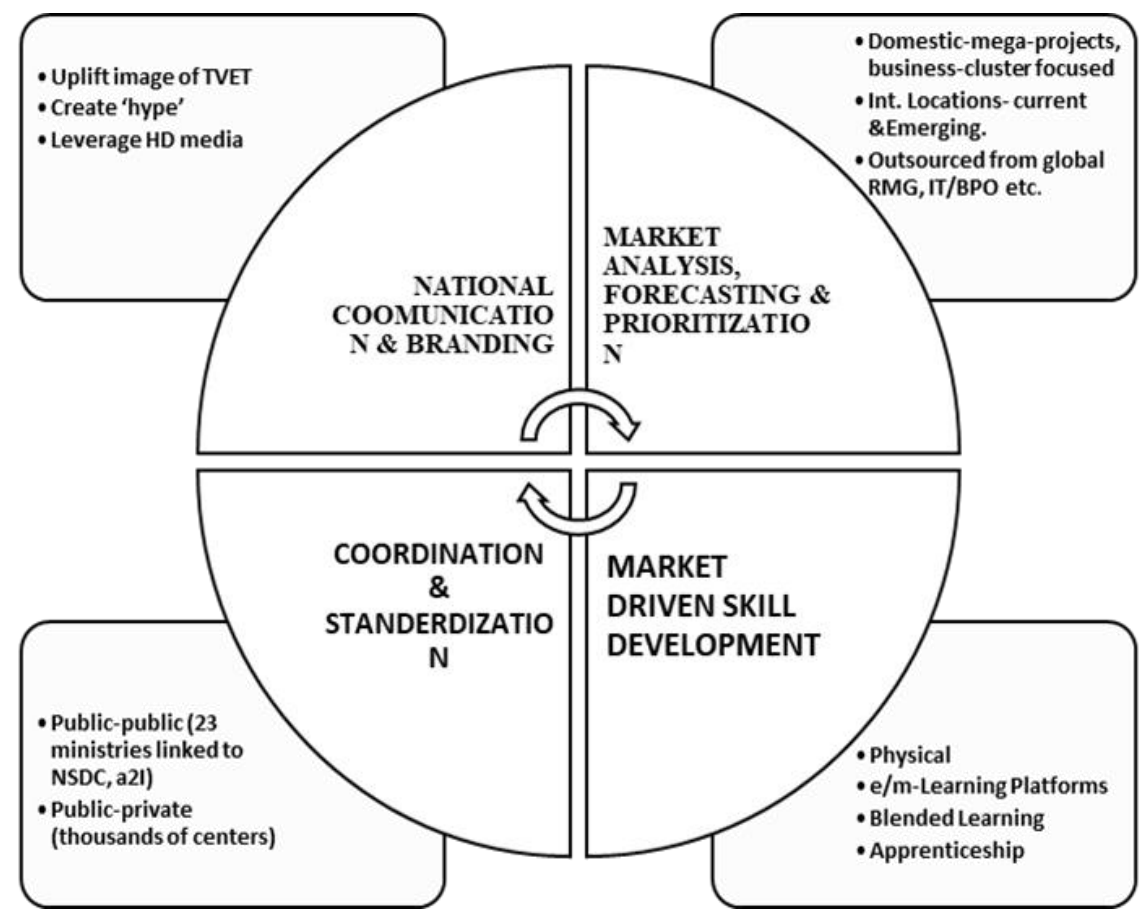


Tasnia Mahin Rafa, Dola kar ,...-Volume 2 - Issue 4-2020, p.373-388.

\section{Impact}

a2i Innovation Lab has a substantial effect on youth, communities and on the attainment of sustainable development goals. The following are some of the major impacts:

a. Increased skills, self-esteem, knowledge and capability

b. Enhanced individual development, as it offers opportunities for young people to bring about meaningful community and sustainable change.

c. Improved social identity and status

d. Improved performance and productivity

e. Insight into Adults' multiple roles and wider career choices

f. Significant youth engagement may strengthen the sense of identity, belonging and appreciation of a young person, which leads to positive mental health

\section{Challenges}

With a total population of approximately over 166 million and a workforce of approximately 82 million, Bangladesh has a youth unemployment rate of 11 percent and an underemployment rate of 19 percent which, according to a 2015 World Bank survey, is moving steadily upwards. The problem, however, is that much of this preparation is outdated, not demand-based, and doesn't include new entrants to the labor market. The education sector is often disconnected from the market. The skills acquired by the former are often unnecessary for them which cause the so-called 'educated' to become unemployed and to be under worked. At the same time, the former fails to build skills that the latter demands that the local workforce cannot satisfy on the market. Such disconnection leads to waste of national capital, dissatisfaction of students on various levels of education, and delayed attainment of domestic economic objectives and sustainable development goals. Tertiary education institute lack the scope or structure to finance the seeds to rapid prototyping solutions.

\section{Recommendation}

The key policy recommendations begin with an initial country-wide evaluation to identify certain segments of society that stayed behind and require appropriate support from a social safety net and also initiatives for youth empowerment. We also suggest making up a national high-level advisory group to develop and implement national strategies for youth employment and sustainable development as well as a monitoring framework to support government performance. We further suggest: revisiting taxes and regulations that restrict the capacity of youth-led start-ups and established companies to invest in the creation of skills in the workforce; introducing a large-scale seed grant 
program organized by local civil society organizations; and local technical training programs aiming at youth in the informal sector. Finally, sub-national governments will need to ground youth employment opportunities initiatives through community service and youth advisory services in the overall context of youth engagement in sustainable development. They should also use financial assistance to motivate public high schools, colleges and universities to open their subsidiary of skills development for working young people.

\section{Conclusion}

The march to middle-income status of Bangladesh needs to be led by the next generation, with their creativity, commitment and optimism. The flight of the country's progress depends on giving the youth greater room to be entrepreneurs, agents of transformation, decision-makers. UNDP supports the Bangladeshi Government and a2i in creating opportunities for positive participation of new generation for sustainable development of the country. This report will motivate all relevant stakeholders to take action to improve performance in the implementation of SDGs in order to reach milestones in the accomplishment of SDGs by the 2030 deadline.

\section{References}

a2i - Access to Information. (2020). Retrieved 22 September 2020, from https://a2i.gov.bd/ Anwar, H. (2010). Youth Problems, Their Development and Empowerment in Bangladesh. $\begin{array}{lllll}\text { ResearchGate. } & \text { Retrieved } 22 & \text { September } & 2020, & \text { from }\end{array}$ https://www.researchgate.net/publication/49600378_Youth_Problems_Their_Develo

Bangladesh - total population 2014-2024 | Statista. (2020). Retrieved 29 August 2020, from https://www.statista.com/statistics/438167/total-population-of-bangladesh/

Express, T. (2020). Youth unemployment - a challenge for economic growth. Retrieved 22 September 2020, from https://thefinancialexpress.com.bd/views/youth-unemployment-achallenge-for-economic-growth-1533741150

Innovation Lab - a2i. (2020). Retrieved 29 August 2020, from https://a2i.gov.bd/innovationlab/\#1509873286563-77f047fa-9255

Khan, A., Javed, A., Batool, S., Hussain, F., Mahmood, H., \& Ahmed, V. (2016). The role of youth in sustainable development: Perspectives from South Asia. Sustainable Development Policy Institute. Retrieved from https://www.think-asia.org/handle/11540/9293

Khan, A., Javed, A., Batool, S., Hussain, F., Mahmood, H., \& Ahmed, V. (2016). The role of youth in sustainable development: Perspectives from South Asia. Sustainable Development Policy Institute. Retrieved from https://www.think-asia.org/handle/11540/9293

Resources - a2i. (2020). Retrieved 22 September 2020, from https://a2i.gov.bd/resources2/\#1509040758595-97781aad-00e0 
Tasnia Mahin Rafa, Dola kar ,...-Volume 2 - Issue 4-2020, p.373-388.

SDG Tracker. (2020). Retrieved 29 August 2020, from https://www.sdg.gov.bd/page/aboutsdgtracker/3\#1

Skills - a2i. (2020). Retrieved 29 August 2020, from https://a2i.gov.bd/skills/\#skills

South-South in Action: Citizen-friendly Public Service Innovation in Bangladesh - a2i. (2020). Retrieved 22 September 2020, from https://a2i.gov.bd/publication/public-serviceinnovation/

Sustainable Development Goals Bangladesh Makes Impressive Progress in Partnership with UNDP | UNDP in Bangladesh. (2020). Retrieved 19 September 2020, from https://www.bd.undp.org/content/bangladesh/en/home/presscenter/articles/2019/10/11/sust ainable-development-goals-bangladesh-makes-impressive-progre.html

Tamesis, P. (2013). Beyond 'out-of-the-box': Youth and innovation in Bangladesh. Retrieved 29 August 2020, from https://www.thedailystar.net/news/beyond-out-of-the-box-youth-andinnovation-in-bangladesh

United Nations - World Youth Report (WYR) | United Nations For Youth. (2020). Retrieved 22 September 2020, from https://www.un.org/development/desa/youth/world-youthreport.html

Youth and the 2030 Agenda for Sustainable Development | United Nations for Youth. (2018). Retrieved 29 August 2020, from https://www.un.org/development/desa/youth/worldyouth-report/wyr2018.html

Youth Social Entrepreneurship and the 2030 Agenda | United Nations For Youth. (2019). Retrieved 22 September 2020, from https://www.un.org/development/desa/youth/worldyouth-report/wyr2020.html

https://a2i.gov.bd/wp-content/uploads/2018/01/Skills-for-Decent-Employment.pdf. Retrieved 22 September 2020.

https://a2i.gov.bd/wp-content/uploads/2019/09/Domestic-Job-Market.pdf. Retrieved

September 2020

https://www.un.org/development/desa/youth/wp-content/uploads/sites/21/2019/02/chapter2wyr-2030agenda.pdf. Retrieved 22 September 2020.

https://think-asia.org/bitstream/handle/11540/9293/commissioned-Paper-The-role-of-youth-insustainable-development-perspectivesfromSouthAsia.pdf?sequence $=1 . \quad$ Retrieved 22 September 2020.

https://a2i.gov.bd/wp-content/uploads/2018/01/Service-Innovation-Fund-1.pdf. Retrieved 22 September 2020. 


\section{APPENDICIES}

\section{Discussion Questions}

1. We know that a simple innovation has helped the cooperative societies to sustain in the long run. Is there any primary objectives a2i- Innovation Lab are providing to the youth of Bangladesh?

Answer: As we know, a2i-Innovation Lab believes in remarkable innovations that can strengthen the nation. Thus the real objective of a2i-Innovations Lab is to solve people's big problems by preserving sustainability and this is the main key goals. Many young innovations help influence traditional views of the development of public environments with the help of this Lab. This could lead society to a change in perception and help educate people about our relationship with biodiversity. These initiatives are also meant to bring communities closer. As key stakeholders, effective youth programs and public attention give visibility to youth. This gives a greater voice to youth in the political sphere, and gives credibility to young people in this sphere, and this influence is supported by a2i-Innovation Lab. Such web-based platforms not only ensure broad e-participation with increased acceptance among people, but can also be used to achieve long-term sustainability by attracting and actively engaging the youth. In addition, to gain greater credibility as a voice within the community, youth can build alliances and collaborations with community organizations, neighborhood councils or other government levels. Gaining political and government support would help to bring pressure on unsupported players by supporting those who are open to the need for environmental sustainability. Youth networking will build a shared voice, exchange ideas and tools of expertise and ensure that all stakeholders are aware of sustainable development decision-making.

\section{What do you think are the major setbacks faced by a2i-Innovation Lab on achieving SDGs of Bangladesh?}

Answer: a2i-Innovation Lab faces major setbacks in Bangladesh's implementation of SDGs. Automation of manual and non-manual routine work, the spread of artificial intelligence in its various forms, evolving business models, political pressures, are causing challenges for a $2 \mathrm{i}$ - Innovation lab to spread its services to the public. These can cause very inconsistent impacts by sector, gender and geography. In Bangladesh, for instance, automation in textiles has already decreased the female share of the labor force. New manufacturing innovations as well as changing business models have affected furniture industry, leading to even more modular production and customer self-assembly. The occasional disconnection of the educational sector and vocational training from the economy is also a challenge for a2i. This is because job market planning is outdated, not demand-driven, and does not include new labor market entrants. Also Institute of Tertiary Education lacks scope or policy to finance effective prototype solutions. The skills of the former are always superfluous, causing the so-called "educated" to be unemployed and working under them. At the same time, the former fails to establish competencies that are not met on the market by the latter. This breakdown leads to the waste of national resources, the dissatisfaction of students at different levels of education and the delayed achievement of domestic economic and sustainable development goals.

3. What would be your recommendation for a2i- Innovation lab for working effectively and efficiently on achieving SDGs of Bangladesh?

Answer: For working effectively and efficiently on achieving SDGs of Bangladesh, the following will be my recommendations for a2i-Innovation Lab. 
Tasnia Mahin Rafa, Dola kar ,...-Volume 2 - Issue 4-2020, p.373-388.

a) Countries which aim to prosper must concentrate both on labor supply and on demand structures. The demand side must include attention to the creation of jobs and the quality of demand for jobs. a2i-Innovation Lab can link them to broader economic strategies to improve investment, productivity and sustainability.

b) They can regularly conduct information and experience sharing forums, in order to educate prospective stakeholders about the program's objectives and accomplishments. Which involves engaging with future innovators who wish to innovate, providing a list of potential cooperation fields of collaboration that can be offered to various organizations, and explaining how the initiative leads to improved communities.

c) They should involve partners in the planning and joint programming of activities, particularly in their field of expertise. And examine, how the private sector may participate particularly on networking issues.

d) E-governance and networking frameworks should be standardized by the a2i-Innovation Lab so that they can generate demand and facilitate change.

e) They should regularly assess their strategies which they follow, so that A2i innovations lab can overcome the major problems facing by society and help Bangladesh toward achieving SDGs.

f) They should mobilize multiple intelligence sources, to make its labor markets adapt quickly and effectively. Which includes data, tacit knowledge, business insights, fact and experience from other countries.

Tasnia Mahin Rafa is an undergrad student and doing her BBA in the Department of Marketing, Bangladesh University of professionals (BUP), Mirpur cantonment, Dhaka, Bangladesh. Her research interests are in the marketing, consumer behavior and entrepreneurship, entrepreneurial orientation, internationalization etc. She is highly interested in writing in national dailies.

Dola Rany Kor is an undergrad student and doing her BBA in the Department of Marketing, Bangladesh University of professionals (BUP), Mirpur cantonment, Dhaka, Bangladesh. Her research interests are in the marketing, government service and education entrepreneurship, technology orientation, and internationalization etc.

Nargis Islam is a research associate at ARB Global Research, a research and consulting firm in Dhaka, Bangladesh. Her research interests are in the areas of international business and entrepreneurship.

Mohammad Osman Gani is a Ph.D., student at Graduate School of Humanities and Social Sciences, Hiroshima University, Japan. He has completed his MSc in Development Science from the Graduate School for International Development and Cooperation, Hiroshima University. He holds a BBA and MBA from the Department of Marketing, University of Dhaka. He also works as an Assistant Professor in the Department of Business Administration in Marketing at Bangladesh University of Professionals, Dhaka, Bangladesh. 